\title{
News: Recognitions, Societies, and Academia
}

Published online: 30 November 2016

(C) The Regenerative Engineering Society 2016

\section{Awards and Recognitions}

Professor Rebecca Richards-Kortum (Malcolm Gillis University Professor, Department of Bioengineering, Rice University) won a 2016 MacArthur Fellowship for her contribution in developing numerous practical biomedical approaches including a portable, high-resolution microendoscope for diagnosis and treatment of cancers. MacArthur Fellowship is one of the most prestigious awards, known as "Genius Grant", and its current prize is $\$ 625,000$. Since 1981, the MacArthur Fellows Program has recognized 942 talented individuals who have exceptional originality, significant achievements, and dedication in their creative pursuits.

Professor Nicholas A. Peppas (Sc. D., Professor and Director of the Institute for Biomaterials, Drug Delivery and Regenerative Medicine, Cockrell Family Regents Chair in Engineering, University of Texas at Austin) was honored with the Robert A. Pritzker Distinguished Lecture Award from the Biomedical Engineering Society (BMES). Professor Peppas was recognized for his leadership and exceptional achievements for advancing science and practice in the field of biomedical engineering.

BMES announced the Class of Fellows for 2016. Recipients were elected based on their outstanding achievements in biomedical engineering with consistent contribution within the society. A list of BMES Class of 2016 Fellows include: Ali Khademhosseini (Ph.D., Professor in the Department of Medicine, Harvard Medical School), Angelique Louie (Ph.D., Professor and Vice Chair in the Department of Biomedical Engineering, University of California, Davis), Bahman Anvar (Ph.D., Professor in the Department of Bioengineering at University of California, Riverside (UCR)), Béla Suki (Ph.D., Professor, Biomedical Engineering, Boston University), Elizabeth G. Loboa (Ph.D.,
Professor and Associate Chair, Joint Department of Biomedical Engineering at UNC-Chapel Hill and NC State University), Jason H. T. Bates (Ph.D., D. Sc., Professor in the Departments of Medicine and Molecular Physiology and Biophysics, University of Vermont), John P. Fisher (Ph.D., Fischell Family Distinguished Professor and Chair in the Fischell Department of Bioengineering, University of Maryland), Sanjay Kumar (M.D., Ph.D., Professor and Associate Chair, Department of Bioengineering at University of California, Berkeley), and Stelios Andreadis (Ph.D., Professor and Chair, Department of Chemical and Biological Engineering, State University of New York at Buffalo).

Professor Douglas A. Melton (Xander University Professor at Harvard University, Co-chair of the Harvard University Department of Stem Cell and Regenerative Biology) was awarded the 2016 Ogawa-Yamanaka Stem Cell Prize and its $\$ 150,000$ prize by the Gladstone Institutes. Professor Melton was recognized for his research on using stem cells for developing insulin-producing beta cells for the treatment of diabetes.

Professor Michael V. Sefton (Michael E. Charles Professor of Chemical Engineering, University of Toronto) received the Lifetime Achievement Award from the Tissue Engineering and Regenerative Medicine International Society (TERMIS) for the year 2016. Professor Sefton was recognized for his lifelong commitment and achievements to the field. Prof. Sefton was one of the first to use scaffolds with cells, effectively pioneering the modern day field of tissue engineering.

Professor Ali Khademhosseini (Professor at Harvard Medical School) was honored with the Senior Scientist Award from the TERMIS for his significant contributions in the field of tissue engineering and regenerative medicine. Professor Khademhosseini has recognized for developing numerous innovative materials and technologies for controlling composition, structure, and function of engineered tissues. 
Professor Molly Schoichet (Professor of Chemical Engineering and Applied Chemistry, Chemistry and Biomaterials and Biomedical Engineering at the University of Toronto, Canada Research Chair in Tissue Engineering) received the 2016 Till \& McCulloh Award, recognizing her contributions to stem cell research and the use of hydrogels for stem cell transplantation. The award is recognized after Drs. James Till and Ernst McCulloh, the pioneers of stem cell biology.

The National Academy of Medicine (NAM) announced 70 new members and nine international members during its 2016 annual meeting. Newly elected members were recognized for their distinguished contributions and achievements in medical science and public health. A list of the new members includes: Francis J. Doyle III (Ph.D., Dean, Harvard Paulson School of Engineering and Applied Science and John A. and Elizabeth S. Armstrong Professor of Engineering and Applied Sciences), Paula Hammond (Ph.D., David H. Koch Professor in Engineering and head of MIT's Department of Chemical Engineering), and Samir Mitragotri (Ph.D., Mellichamp Chair Professor in the Department of Chemical Engineering at University of California, Santa Barbara).

\section{University Positions}

Professor George Q. Daley (Robert A. Stranahan Professor of Biological Chemistry and Molecular Pharmacology, Medicine, and Pediatrics at Harvard Medical School), an internationally renowned researcher in stem cell biology and cancer, was appointed as the Dean of Harvard Medical School (HMS). He currently serves as the director of the Stem Cell Transplantation Program at Boston Children's Hospital and the Dana-Farber Cancer Institute, as well as a professor at Harvard Medical School. Professor Daley will begin his new position effective Jan 1st, 2017.

\section{Views: Recent Advances in the Field}

\section{Advancements in Industry}

AiVita Biomedical, an Irvine, CA based company developing stem cell technologies, received an R01 grant from the National Eye Institute (NEI), National Institute of Health (NIH). AiVita will manufacture stem cell-derived transplantable retinas to cure vision loss. Sue and Bill Gross Stem Cell Research Center at University of California Irvine will collaborate with AitVita for testing safety and efficacy of the product in retinal degeneration models.
Poietis, a Pessac, France based biotechnology company creating human tissues for regenerative medical purposes, made partnership with L'Oreal to bioprint functional hair follicles, the skin organ that grows hair. L'Oreal has dedicated itself to tissue engineering for the last 30 years and has extensive experience with hair biology. During this multi-annual research partnership, Poietis will use its unique laser-assisted bioprinting technology with extremely high resolution for hair engineering.

\section{Advancements in Academia}

Scientists at Massachusetts Institute of Technology have developed a wearable second skin by utilizing skin-adherent polysiloxane-based crosslinkable polymer materials with tunable elasticity and tensile strength. This wearable crosslinked polymer layer (XPL) looked similar with healthy normal skin and exhibited enhanced skin barrier function. In a human pilot study, a tensile modulus of a prototype XPL matched well with normal skin, withstanding elongation more than $250 \%$. The XPL second skin platform can be potentially applied for wound dressing. This research was published in Nature Materials.

Scientists at Seoul National University have developed a skin-mounted, graphene-based electrochemical patch for monitoring and treating diabetes. This wearable, stretchable patch consists of sensors that can monitor glucose level in sweat and thermoresponsive polymeric microneedles that can deliver drugs transcutaneously. When glucose concentration is high, embedded heaters are triggered to dissolve biodegradable polymeric microneedles to release drugs. This diabetes patch study was published in Nature Nanotechnology.

\section{Philanthropic Support}

Facebook co-founder Mark Zuckerberg and Priscila Chan announced a $\$ 3$ billion plan to bring teams of scientists and engineers with an ambitious goal of preventing and curing all diseases before the end of this century. Bill Gates, co-founder of Microsoft Corp. also supported this plan. As an initiative step, a $\$ 600$ million will be funded over 10 years to establish a new research center, the Chan Zuckerberg Biohub, in partnership with Stanford University, University of California, Berkeley, and University of California at San Francisco (UCSF). Professor Joseph DeRisi (Professor and Chair of the Department of Biochemistry and Biophysics at the UCSF) and Stephen Quake (Professor of bioengineering and applied physics at Stanford University) will co-lead the Biohub. 